\title{
DON QUIJOTE Y LA MIMESIS POÉTICA
}

Marcela Solís-Quiroga*

Así que las descripciones de tiempos, lugares, palacios, bosques y semejantes, como sean con imitación y verosimilitud, serán poemas: y no lo serán si de imitación carecen.

Pinciano $^{1}$

Mucho se ha reflexionado, a lo largo de la historia de la cultura, sobre el proceso de la creación literaria para tratar de dilucidar, en la medida de lo posible, cuáles son los artilugios de los que se vale el escritor para estructurar cada uno de los mundos representados en una obra, llámese novela, cuento, poema o ensayo. Dichas reflexiones no son más que el producto de un análisis con un enfoque determinado y parcial, que no nos revelará en su totalidad los misterios que el proceso creativo entraña ni los que son inherentes a la obra misma. Muchos han sido los interesados en descubrir aquello que le otorga un carácter universal a textos que, como El ingenioso hidalgo don Quijote de la Mancha $(1605,1615)$ son considerados parte del acervo cultural básico. Pero, ¿a qué se debe que la magna obra de Miguel de Cervantes siga vigente a pesar del paso del tiempo y del cambio de ideologías. Para algunos, la universalidad y vigencia del arte literario radica en los temas, en el contenido de un texto; para otros, en cambio, en el tratamiento de éstos, en la forma de expresar lo

* Facultad de Filosofía y Letras, UNAM.

${ }^{1}$ Pinciano López, Philosophia Antigua Poética, 1951, Madrid, Instituto Miguel de Cervantes, p. 265. 
que se desea dar a conocer, en el estilo, en aquello que, sin que el lector se percate, renueva cada lectura, haciéndola única e irrepetible. En lo personal, creo que ambos planos, forma y contenido, garantizan el flujo de interpretaciones de un texto.

En el caso del Quijote, se entrelazaron un sinfín de características y elementos literarios, históricos, filosóficos y estéticos, que hicieron que esta obra ganara popularidad, trascendiera toda clase social y fuera adaptada y traducida a múltiples idiomas. Los filólogos, investigadores de la literatura o críticos literarios no se cansan de indagar sobre esta obra y su peculiar protagonista, don Quijote, ya que, a diferencia de otros textos incluidos en el 'canon literario', no deja de producir nuevas sensaciones y pensamientos, interpretaciones, dudas, corajes, sonrisas y lágrimas. El estilo cervantino, dado su espíritu lúdico, siempre nos parece moderno; su prosa nos atrapa en un laberinto de magia y realidad, nos interroga sobre la esencia de los acontecimientos del pasado y del presente, así como sobre las posibilidades del destino humano en el futuro, pero, sobre todo, nos produce un placer que rebasa lo estético para impregnarnos aún más de esas contradicciones y paradojas que le dan sentido a cada uno de los avatares de don Quijote.

94 Por ello, resultaría ingenuo imaginar a Cervantes tratando de ceñirse a las reglas y esquemas poéticos en boga, ya que si bien es cierto que el escritor pertenece a una tradición literaria determinada, también lo es el hecho de que reinterpreta la tradición.

Cervantes era un hombre inconforme con su época. No es gratuito que haya tomado como pretexto la parodia de las novelas de caballerías para denunciar, veladamente y bajo la bandera retórica de 'enseñar divirtiendo', la decadencia de ciertos valores que se consideraban, en los siglos XVI y XVII, como 'absolutos y verdaderos'. En el Quijote se hace notar, mediante la figura del caballero andante, del hombre idealista y poco convencional, del 'loco', la relatividad de la realidad, la subjetivación de lo aparentemente objetivo. Don Quijote nos muestra que la noción de realidad es polivalente y cambiante desde su condición libresca e imaginaria, en la que lo más importante es lo imprevisible, la confusión, el juego, los límites poco marcados entre lo real y lo 
ficticio. Por ello, por la condición de poeta inherente al idealista y platónico don Quijote, en el presente ensayo centraré mi atención en el primer capítulo de la novela cervantina, donde se anuncian los motivos por los que Alonso Quijano perdió la cordura y se deja entrever cuál será la base de las distintas percepciones de la realidad adoptadas a lo largo de la novela.

Este primer capítulo, aunque constituye una muestra diminuta de lo que significa la obra en sí, al mismo tiempo nos presenta elementos interesantes de análisis, como la locura, el acto de leer y el desdoblamiento del lector, la importancia de la verosimilitud en la creación literaria, entre otros; pero, sobre todo, nos invita a profundizar en la percepción platónico-quijotesca de la realidad, en la que ésta es un reflejo que impide el conocimiento de la verdad, en la que la mimesis es la imitación de la apariencia, asumida, en ocasiones, como 'verdad', y en otras, como fantasía. Por tal motivo, en las siguientes páginas reflexionaré en torno a la conexión que existe entre la percepción de la realidad de don Quijote en el primer capítulo y la noción intrínseca a ésta: la mimesis poética -según Aristóteles y Pinciano.

Desde el primer capítulo de El ingenioso hidalgo don Quijote de la Mancha, don Alonso Quijano, al haber perdido la cordura, se desenvuelve tanto en el ámbito de lo real como en el de lo imaginario. El hecho de que el hidalgo haya perdido las nociones de realidad por leer en exceso novelas de caballerías es un indicio del proceso que todo lector ha pasado cuando se introduce en el universo literario; de las simpatías y antipatías que se establecen con los personajes debido a su corporeidad y a la encarnación de su ser, así como a la abstracción y el esfuerzo mental que toda obra exige para su comprensión. Una lectura sin la concentración necesaria no cobra vida, se convierte en un mero papel con manchas ininteligibles de tinta. En este sentido, el paso que da don Quijote de lo 'real' a lo 'ficticio' se reitera cuando el caballero andante abre una nueva novela y se interna -como nosotros lo hacemos cuando leemos sus hazañas- en el mundo fantástico en que viven los caballeros, quienes, a pesar de no comer ni dormir, se le figuran cada vez más reales: 
Llenósele la fantasía de todo aquello que leía en los libros, así de encantamientos como de pendencias, batallas, desafíos, heridas, requiebros, amores, tormentas y disparates imposibles; y asentósele de tal modo en la imaginación que era verdad toda aquella máquina de aquellas sonadas soñadas invenciones que leía, que para él no había otra historia más cierta en el mundo. ${ }^{2}$

La locura de don Quijote es la de quienes imaginan, sienten y viven la literatura con esa intensidad que se asemeja a la de la existencia misma; es el delirio que sufre toda persona capaz de identificarse con otra y de asumir los conflictos internos o externos de los personajes como propios. No es gratuito que Cervantes describa a don Quijote como un hombre de constitución física débil, a quien se le conocía por sus múltiples sobrenombres, en un lugar indeterminado de la Mancha: el hidalgo 'Quijada' o 'Quesada', como en un principio nos lo presenta el narrador. La locura de don Quijote se relativiza; su peculiaridad, entonces, consiste en no estar dentro de los parámetros de la normalidad: transgredir los valores sociales -que dentro de la ficción se hallan en una crisis que corresponde a la realidad extratextual-y preferir el mundo novelado al propio para efectuar los cambios que cree convenientes en su entorno.

Pero, ¿acaso la transgresión y la evasión, así como la imaginación y la fantasía es propia y exclusiva de los locos? No. Sin embargo, los extremos a los que llega don Quijote lindan con una percepción del mundo aparentemente desligada de la realidad, de modo que, a veces, si miramos sus acciones desde el punto de vista meramente racionalista, nos parecen absurdas y ridículas. En cambio, en muchas otras ocasiones, nos sorprende que el discurso de este personaje esté tan bien estructurado que devela un profundo conocimiento de la psicología y comportamientos humanos, que nos hace reflexionar sobre los grandes temas que siempre han asediado al hombre: el poder, la riqueza, la

${ }^{2}$ Miguel de Cervantes, Don Quijote de la Mancha I, "Capítulo primero. Que trata de la condición y ejercicio del famoso hidalgo don Quijote de la Mancha”, 1991, México, Edición de J. Jay Allen, REI, p. 100. 
muerte, la sobrevivencia... En este sentido, la contradicción entre un discurso bien articulado racionalmente y otro empapado de fantasías e imaginación no existe en don Quijote, sino que es parte de su mirada fragmentaria hacia lo que le rodea. Una vez que asumimos que don Quijote es la creación encarnada de un hombre al que se le "secó el celebro de manera que vino a perder el juicio", 3 no nos extrañan sus bruscos cambios en el modo de percibir su 'realidad' o ¿su eterna ficción? De hecho, la duda que nos asalta a cada momento es si lo que está ocurriendo en la novela es 'verdad' o 'ficción'; es decir, si la ficción que estamos leyendo no es la envoltura de nuevas ficciones que se pierden y confunden en el cosmos de la ilusión. Esta duda es la prueba de que don Quijote es un personaje verosímil que hace que nos interroguemos por nosotros mismos, por nuestro modo de ser y existir en el mundo. La verosimilitud de un personaje no depende de lo extraliterario, sino de la articulación exacta entre el entorno, el lenguaje, las situaciones e ideas, así como la lógica interna del personaje trenzada en cada una de las lógicas noveladas. La locura 'quijotesca' es -como señala Erich Auerbach- "la que conjura y desata todo el juego; es ella la que hace del mundo real y cotidiano un divertido escenario". 4

Así, el enredo, los personajes y las ideas que se conjugan en una narración resultan un conjunto inseparable para que el texto adquiera un significado pleno. Al respecto, señala Antonio Cándido que, aunque el personaje constituye el elemento más comunicativo en el arte de novelar, sólo es posible comprenderlo cabalmente en su entorno. ${ }^{5}$ Por tal motivo, el problema de la verosimilitud vinculado a las afinidades y diferencias entre un ser 'real' y uno 'ficticio' cobran una gran relevancia en la recepción, nos invitan a reflexionar sobre nuestro fragmentario modo de contemplar el mundo, a confrontarlo con aquello que nos permite aprehender la esencia de un personaje de ficción: el hecho de que es el retrato de un microcosmos que podemos contemplar en su totalidad.

${ }^{3}$ Ibid., p. 100.

4 "La dulcinea encantada", en Mimesis, 1996, México, FCE, p. 331.

${ }^{5}$ Cfr. Antonio Cándido, El personaje de novela, México, Siglo XXI, en prensa. 
La representación, el volver a presentar, es lo más importante en las manifestaciones artísticas. Ese volver a presentar es justamente lo que Aristóteles llamó mimesis en su Arte poética: imitar para recrear, para conocer lo que nos resulta ajeno, haciéndolo nuestro. La mimesis, dice Aristóteles, es la inclinación natural del hombre y la primera fuente de conocimiento. ${ }^{6} \mathrm{El}$ arte, al ser netamente humano, participa de esta inclinación: la "poesía -señala Pinciano- no es otra cosa que arte que enseña a imitar con lengua o lenguaje". ${ }^{7}$ La diferencia entre imitar a la naturaleza, como hace el niño, e imitar el mundo, como pretende el arte, radica no sólo en los recursos de los que éste se vale para retratar, sino, sobre todo, en la pretensión totalizadora del artista, quien no busca elaborar un retrato de los objetos, pero sí de los posibles y multicolores mecanismos que relacionan lo objetivo con lo subjetivo. Cuando ese retrato cobra vida por sus propios medios, entonces resulta verosímil. En don Quijote, el eje que le da coherencia y verosimilitud a sus acciones es su condición de loco, ya que de una persona que ha perdido el 'juicio' se espera cualquier reacción, hasta lo inimaginable: la racionalidad unida a la pasión extrema. Baste recordar la racionalidad de don Quijote aplicada a la selección del nombre que su caballo llevaría a lo largo de su devenir andante, así como la pasión que motivó al hidalgo para llevar a cabo dicha empresa:

...así, después de muchos nombres que formó, borró y quitó, añadió, deshizo y tornó a hacer en su memoria e imaginación, al fin le vino a llamar Rocinante, nombre, a su parecer, alto, sonoro y significativo de lo que ahora era, que era antes y primero de todos los rocines del mundo. ${ }^{8}$

Por otra parte, es innegable que sin una estructura fuerte y sin el uso adecuado de las palabras, un mensaje deja de ser claro y efectivo en términos de comunicación. La mayor parte del primer capítulo del Quijote está dedicado a la reflexión en torno al proceso de lectura, a la

\footnotetext{
${ }^{6}$ Cfr. Aristóteles, El arte poética, 1986, México, Espasa Calpe, Colección Austral, p. 31.

${ }^{7}$ Pinciano López, op. cit., p. 279.

${ }^{8}$ Miguel de Cervantes, op. cit., p.102.
} 
experiencia estética y cognoscitiva de los personajes que guiarán el camino del héroe en su locura. Asimismo, nos presenta el nacimiento del caballero andante, así como de su dama, Dulcinea del Toboso, quien, en realidad "llamábase Aldonza Lorenzo, y a ésta le pareció [a don Quijote] ser bien darle título de señora de sus pensamientos; y buscándole nombre que no desdijese mucho del suyo, y que tirase y se encaminase al de princesa y gran señora, vino a llamarla Dulcinea del Toboso, porque era natural del Toboso; nombre, a su parecer, músico y peregrino y significativo, como todos los demás que a él y a sus cosas había puesto". 9

Resulta interesante cómo el hidalgo, antes de llamarse a sí mismo don Quijote, y de nombrar 'Rocinante' a su caballo, busca que su mundo -incluido su nombre- tenga coherencia con la literatura, con los libros de caballerías. De este modo, Alonso Quijano es creador y actor de su propio personaje, al querer imitar -realizar una mimesis - a los caballeros andantes de las novelas. Lo curioso es que Alonso Quijano es la representación de un hidalgo ocioso que de tanto leer quiere imitar las aventuras imaginarias de los escritores que, a su vez, pretendían mostrar un aspecto de lo humano, la valentía, por medio de la mimesis de los modelos caballerescos. En este sentido, podemos afirmar que don Quijote representa la mimesis de la mimesis poética, y que en la obra se saben articular a la perfección los recursos retóricos y narrativos que, al final, contribuirán a producir una verosimilitud de carácter unitario. La importancia de nombrar adecuadamente el mundo que rodearía al nuevo caballero andante muestra que imitar no es calcar un modelo, sino hacer de éste un boceto que debe retocarse y modificarse hasta obtener lo deseado. Lo mismo que hizo don Quijote con su mundo, Cervantes lo realizó en su magna novela, y ambos demiurgos fueron rebasados por su propia obra. Ya críticos como Auerbach lo han señalado:

${ }^{9}$ Ibid., p. 103. 
Un libro como el Quijote está llamado, por fuerza, a desembarazarse de las intenciones de su creador, para vivir una vida propia; presenta una nueva faz a cada época que se complace en él. ${ }^{10}$

El Quijote pretendía mostrar la complejidad de las relaciones humanas que, en general, se extiende al juego poético-retórico de la intertextualidad. La lectura era una actividad de ocio y, por tal motivo, necesitaba recurrir a la amenidad y a la diversión, pero también a las ideas que le pudieran otorgar armas al lector para que descubra los diversos significados de la obra. Cuando el narrador afirma que "con estas razones perdía el pobre caballero el juicio y desvelábase por entenderlas y desentrañarles el sentido, que no se lo sacara ni las entendiera el mesmo Aristóteles, si resucitara para solo ello", ${ }^{11}$ alude a la búsqueda de esos significados e incluso exalta irónicamente la figura de Aristóteles, quien tenía como prioridad desentrañar el sentido de la realidad. Don Quijote, como lector voraz, no sólo se sentía parte de la historia de ficción y disfrutaba de las aventuras, sino que también buscaba hallar en ellas un sentido, una enseñanza de vida. El ingenioso hidalgo creaba y recreaba sus mundos, sin olvidar nunca que la pura imaginación no es suficiente para crear fantasías, sino que resulta indispensable ordenar impresiones e intuiciones, fundir razón y pasión en un acto creativo: mimetizarse en la figura del demiurgo que se crea y destruye al mismo tiempo... el inevitable espejo de nuestros días.

${ }^{10}$ Op. cit., p. 333.

11 Ibid., p. 98. 